\title{
Retinal ganglion cells of high cytochrome oxidase activity in the rat
}

\author{
JEN LS*1 AND GHAU RMW** \\ *Department of Anatomy, Chinese University of Hong Kong, \\ **Department of Anatomy, University of Hong Kong
}

\begin{abstract}
Retinal ganglion cells in the rat wore studied using the heavy metal intensified cytochrome oxidase and horseradish peroxidase histochemical methods. The results show that a population of large retinal ganglion cells was consistently observed with the cytochrome oxidase staining method in retinas of normal rats or rats which received unilateral thalamotomy at birth. Those eytochrome oxidase rich ganglion cells appeared to have large somata, 3-6 primary dendrites and extonsive dendritic arbors, and are comparable to ganglion cells labeled by the wheat germ agglutinin conjugated to horseradish peroxidase (WOAHRP). However, the morphological details of some of the cells revealed by the cytochrome oxidase staining method are frequently better than these shown by the HRP histochemieal method. These results suggest that the mitochondrial enzyme cytochrome oxidase can be used as a simple but reliable marker for identifying and studying a population of retinal ganglion cells with high metabolic rate in the rat.
\end{abstract}

Key words: Cytochrome oxidase, WGA-HRP, Retinal ganglion cells, Rat.

\section{INTRODUCTION}

It has long been recognized that the mitochondrial enzyme cytochrome oxidase can be used not only for revealing neurons or brain regions of high oxidative metabolic activity, but can also be used as an marker enzyme for neurons or anatomical entities of the brain with certain special physiological properties [6-9, 12-14,17,18,24-26] In the retina, it has been demonstrated in a variety of mammalian species that the cytochrome oxidase histochemical technique is useful for staining a population of ganglion cells with relabively large somata [13-15] However, in most of the cases reported, the dendrites of the retinal ganglion cells especially their secondary and more distal branches can not be visualized using the cytochrome oxidase histochemistry, In view of the fact that the dendritic morphology has

1 Correspondence: LS JEN, Department of A natomy, Chinese Uaiversity of Hong Kong, Shatin, N. T., Hoag Kong. 
Cytochrome oxidase rich retinal ganglion cells

become an important feature for studying or classifying ganglion cells $[1,4,5,19,22]$ it is to our interest to find out that whether the cytochrome oxidase histochemical technique can be modified to such an extent that it can stain not only the somata of neurons but also their dendritic arbors. In this study, our attention is given to a populabion of large or alpha-like retinal ganglion cells which is known to constitute only a small percentage of the ontire population of ganglion cells in the rat robina [13, 15, 23]. The application of the modified cytochrome oxidase histochomical method in studying plastic changes of dendritic arbors of retinal ganglion cells was also discussed. For comparison, rebinal ganglion cells labeled by another neuronal marker, the wheat germ agglutinin conjugated to horseradish peroxidase (WGA-HRP) were also studied.

\section{MATERIALS AND METHODS}

Five litters of Sprague-Dawley rats were used in this study. The animals were divided into two groups. The first group consists of normal rats, whereas the second group of rats received left thalamotomy at birth (Fig. 1). The purpose of the thalamic lesion was to remove most if not all of the contralaterally projecting retinal ganglion cells, which is known to result in rescuing a population of ipsilaterally projecting retinal ganglion cells and considerable remodeling of their dendribie trees in the temporal part of the retina
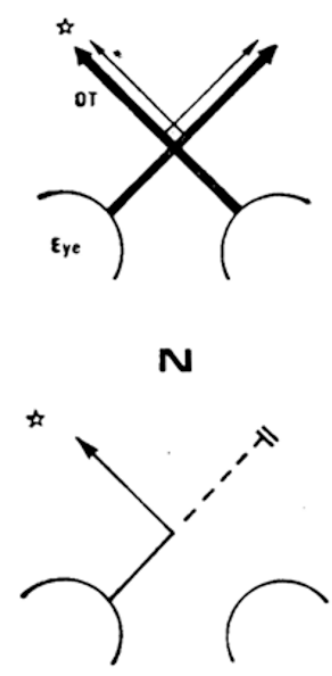

$\mathbf{T}$

Fig. 1 Schematic drawings illustrating the retinofugal projections in normal rats $(\mathrm{N})$ and rats with neonatal thalamic lesion ( $\mathrm{T}$ ) on the left side. Note that the retinofugal projections in the rat are predominantly crossed (thick solid lines with arrows). The broken line represents the abolished crossed projections in the lesioned rats. The asterisks indicate the sites of implantation of WGA-HRP.

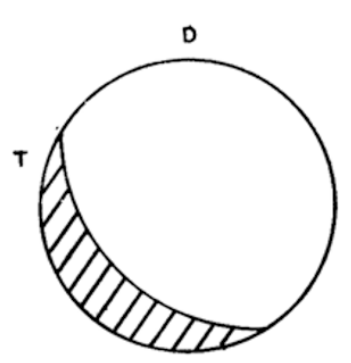

Fig. 2 A schematic drawing illustrating a wholemount rat retina. The shaded area represents the temporal crescent of the retina where the ipsilaterally projecting retinal ganglion cells are mainly distributed, The part of the retina nasal to the central border of the temporal crescent is considered as the nasal retina. $\mathrm{D}$, dorsal; T, temporal. 
(Fig. 2) [2, 3, 11, 13, 16] The neonatal lesions were performed on newborn rats under ether anesthesia. The skin and calvarium overlying the occipital cortex of rat pups was out open, and the cortex and hippocampus above the dorsal posterior part of the thalamus were removed by aspiration under visual guidance with a glass pipette connected to a suction pump $[4,9]$. The wound was sutured and the rat pups together with their normal littermates were returned to their mothers and raised until one and half months old before sacrifice. Three days before perfusion, some of the animals including normal rats and rats with neonatal lesions received an implant containing WGA-HRP in the right optic tract. This was done by introducing a piece of previously air-dried gelfoam containing WGA-HRP into the dorsal lateral geniculate nucleus on the right side (Asterisks in Fig. 1). All animals were deeply anesthetized by chloral hydrate $(7 \%, 0.5 \mathrm{ml} / 100 \mathrm{~g}$ body weight) and then perfused transcardially by physiological saline followed by $1 \%$ glutaraldehyde and $1.25 \%$ paraformaldehyde in $0.1 M$ phosphate buffer. The eyes of the rats with their dorsal pole marked by a cut were removed and the retinas dissected out in phosphate buffer. The brains were collected and sunk in $30 \%$ sucrose-buffer before they were frozen sectioned at $30 \mu \mathrm{m}$ thickness. The retinas were divided into two groups which were processed either for cytochrome oxidase or horseradish peroxidase histochemistry. For revealing cytochrome oxidase activity, the retinas were washed with phosphate buffer and then incubabed in a phosphate buffer solution containing $0.5 \%$ diaminobenzidine, $0.3 \%$ cobalt chloride and $0.3 \%$ cytochrome C (Sigma, C-2506) at $37^{\circ} \mathrm{C}$ for two hours. Some of the retinas were processed for HRP reaction using the heavy metal intensified protocol as described elsewhere $[3,11]$. The retinas of right eyes obtained from 12 normal rats and 14 rats with neonatal lesions were included in the present study. The others were discarded due to unsatisfactory reaction and thalamic lesion which failed to eliminate the entire left optic tract.

\section{RESULTS}

In general, the cytochrome oxidase technique stained selectively a population of large cells in the ganglion cell layer regardless of the sources of the retinas. In normal rats, the cytochrome oxidase reactive cells were fairly evenly distribubed across the entire retina (Fig. 3A), a pattern similar to that described in previous studies[13-15]. The great majority of the cells appeared to have relatively largo somata with a diameter varying from 18 to more than $25 \mu \mathrm{m}$. These cells were usually multipolar in shape with 3-6 primary dendrites running in different directions (B, C \& D in Fig. 3). The secondary, tertiary and oven more distal branches were frequently observable in many cases. although the intensity of staining decreased gradually towards the berminal dendritic endings.

The cytochrome oxidase reactive cells in bhe ganglion cell layer: in right retinas of rats with neonatal thalamic lesion appeared to concentrate primarily in the far periphery of the temporal retina, an area which is known as the temporal crescent of the retina (Figs. 2 and 4B). Only a very small number of eytochrome oxidase reactive cells were scattered in the nasal part of the retina. Interestingly, the cytochrome oxidase rich cells located in the temporal crescent had a completely different dendritic pattern as compared with cells situated in corresponding part of the retina in normal rats. As shown in B, C 
and D in Fig. 4, the cytochrome oxidase rich cells located in or near the central border of the temporal crescent had their dendritic trees biased strongly towards the nasal part of the retina. In fact, the entire dendritic arbor of many cells located in the temporal crescent was found to be located on the nasal side of the somata. The dendritic arbors of the cytochrome oxidase reactive cells located in the nasal part of the retina of rats with neonatal lesion was basically similar to those observed in normal retinas. They were multipolar in shape and had several primary dendrities which extended from the cell body and ramified with no orientational preference.

Another feature about the cytochrome oxidase reactive cells which needs to be mentioned is the laminar distribution of dendrites of the cells in different sublaminae of the inner plexiform layer. While the dendrites of most of the cytochrome oxidase rich ganglion cells appeared to ramify in the sublamina b or inner part of the inner plexiform layer, a small number of cells with their dendrites distributed in the sublamina a or outer part of the inner plexiform layer was also noticeable (Fig. 4C). The reason that more cells which ramified in the sublamina b than in sublamina $a$ is probably due to a better infiltration of the chemicals or reagents in the more superficially located dendritic arbors.

In preparations reacted for horseradish peroxidase histochemistry, the number of WGA-HRP labeled retinal ganglion cells was considerably higher than that revealed by the cytochrome oxidase method, and the majority of the labeled cells were distributed in the temporal crescent, as expected (Fig. 4A). Furthermore, retinal ganglion cells of all sizes were labeled and their primary dendrites were invariably observable. The primary and secondary dendrites were distinct in cells with large somata, although more distal branches were relatively lightly labeled as compared to that shown by cytochrome oxidase. In normal rebiuas, the primary dendrites of most of the labeled cells tended to be spread out in all directions with no strong bias as to which direction they ramified. In retinas obtained from lesioned animals, however, the dendribes of many of the cells located in the temporal crescent were clearly biased towards the nasal part of the retina which was depleted of ganglion cells. On the other hand, cells in the nasal part of the retina did not show any preference in their dendritic orientation. The dendritic arbors of cells in this part of the retina were not significantly different from those cells observed in the normal retina.

\section{DISCUSSION}

The present study in the rat has demonstrated that the heavy metal intensified eytochrome oxidase method is useful in revealing dendritic morphology of a population of retinal ganglion cells. This population of cytocrome oxidase reactive retinal ganglion cells appeared to have large somata and several primary dendrites, thus resembling the alpha or $\mathrm{Y}$ type retinal ganglion cells described in previous reports[1, 4, 5,19,22]Therefore, this method provides a simple but useful way for studying a population of large retinal ganglior cells with high metabolic activity. The reason why the dendrites of smaller retinal ganglion cells were not stained is not altogether clear, although it is possible that the intensity of staining may reflect the actual amount of the enzyme molecules present in 
the cells and their processes. In other words, the larger cells which presumably contain more enzymes can be stained better with the cytochrome oxidase technique. The lack of distinct labeling of cells with small somata supports previous observations that nonganglion cells contribute very little to the cytochrome oxidase activity in the retina under normal condition $[13,15]$. On the other hand, the selective staining of the large retinal ganglion cells by the cytochrome oxidase method implies that these cells are more active than the smaller ones. If that is the case, the finding of a population of large retinal ganglion cells with high cytochrome oxidase activity in the temporal retina seems to coincide with the observation of a high density of large retinal ganglion cells located in a region in the temporal retina where the midline of the visual field is represented $[15,23]$. It is also worth noting that many of the large cells located in the temporal crescent probably contribute to the uncrossed retinofugal pathways under both normal and experimental conditions $[2,3,11,13,16,20]$. This is supported by the observation of a significant increase in the number of large retinal ganglion cells which project ipsilaterally, and large cells with high eytochrome oxidase activity, as revealed by horseradish peroxidase and cytochrome oxidase histochemical methods respectively. Further evidence for this arises from the observation of retinal ganglion cells with strongly biased dendritic arbors towards the nasal part of the retina in rats which received neonatal thalamic lesion as demonstrated by the two histochemical techniques used in this study. The fact that many of the cells with their dendritic arbors biased in nasal direction can be explained as a result caused by competition for trophic factors available in local region, as proposed by Perry and Maffei[21]. The dendrites therefore tend to grow in nasal direction into retinal regions where few retinal ganglion cells are preserved and the competition is much less severe. Whereas for cells in the nasal part of the retina, the supply of trophic substances in nearby region is relatively equally distributed, the dendrites of these cells are more evenly spread out and a strong preference in orientation of the dendrites was not observed. In any events, our findings showing that the dendritic morphology of a population of ipsilaterally projecting retinal ganglion cells is similar to that revealed by cytochrome oxidase histochemistry imply that these cells are metabolically highly active. Whether the cytochrome oxidase rich ipsilateral cells represent a population of cells with special physiological properties is certainly an interesting issue which remains to be determined by further experimentation.

\section{ACKNO WOEDGEMENT.}

This study was supported by UPGC research grant 221400030 and Croucher Foundation research grant 360-031$1792-4 \mathrm{~F}$

\section{REFERENCES}

[1] Boycott BB and Wassle H. The morphological types of ganglion cells of the domestic cat's retina. J Physiol 1974; 240: $397-419$.

[ 2 ] Chan SO and Jen LS. Enlargement of uncrossed retinal projections in the albino rat: additive effects of neonatal eye removal and thalamectomy. Brain Res 1988; 461: 163-168.

[3] Chan SO, Chow KL and Jen LS. Postnatal development of the ipsilaterally projecting retinal ganglion cells in. normal rats and rats with neonatal lesions. Dev Brain Res 1989; 49: 265-274.

[4] Dann JF, Buhl EH and Peichl L. Dendritic maturation in cat retinal ganglion cells: A Lucifer Yellow study. 


\section{Cytochrome oxidase rich retinal ganglion cells}

Neurosci Lett 1987; 80: 21-26.

[ 5 ] Dann JF, Buhl EH and Peichl L. Postnatal dendritic maturation of alpha and beta ganglion cellw in cat retina. J Neurosci 1988; 8: 1485-1499.

[ 6 ] Dietrich WD, Durham DB, Lowry OH and Woolsey TA. Quantitative histochemical effects of whisker damage on single identified cortical barrels in the adult mouse. J Neurosci 1981; 1: 929-935.

[ 7 ] Horton JC and Hubel DH. Regular patchy distribution of cytochzome oxidase staining in primary visual cortex of macaque monkey. Nature 1981; 292: 762-764.

[ 8 ] Humphrey AL and Hendrickson AE. Background and stimulus-induced patterns of high metallic activity in the. visual cortex (area 17) of the squirrel and macaque monkey. J Neurosci 1983; 3: 345-358.

[ 9 ] Itaya SK, Itaya PW and Van Hoesen GW. Intracortical termination of the retino-geniculo-striate pathway studied with transsynaptic tracer (wheat germ agglutiniu-horseradish peroxidase) and cytochrome oxidase staining in the macaque monkey. Brain Res 1984; 304: 303-310,

[10] Jen LS and Lund RD. Experimentally induced enlargement of the uncrossed retinotectal projection in the rat Brain Res 1981; 211: 37-57.

[11] Jen LS, Chan SO and Chau RMW. Preservation of the entire population of normally transient ipsilaterally projecting retinal ganglion cells by neonatal lesions in the rat. Exp Brain Res 1990; 80: 205-208.

[12] Jen LS, Chau RMW and Tsang D. Cytochrome oxidase activity in retinas transplanted to the brainstem in rata_ Neurosci Left 1989; 105: 275-280.

[13] Jen LS, Zhao LP and Ghau RMW. Cytochrome oxidase activity in the rat retina following unilateral thalamic lesion. Neurosci Lett 1989; 103: 133-138.

[14] Kageyama GH and Wong-Riley M. The histochemical localization of cytochrome oxidase in the retina and LGN of the ferret, cat, and monkey, with special reference to retinal mosaics and ON-/OFF-center visual channels. $\mathrm{J}$ Neurosci 1984; 4: 2445-2459.

[15] Land PW. Dependence of cytochrome oxidase activity in the rat ateral geniculate nucleus on retinal innervation. J Comp Neurol 1987; 262: 78-89.

[16] Linden R and Serfaty GA. Evidence for differential effects of terminal and dendritic competition upon, developmental neuronal death of the retina. Neuroscience $1985 ; 15$ : 853-868.

[17] Livingstone MS and Huhel DH. Specificity of cortico-cortical connections in monkey visual system. Nature 1983; 304: 531-534.

[18] Livingstone MS and Hubel DH. Connections between layer 4B of area 17 and the thick cytochrome oxidase stripes of area 18 in the squirrel monkey. J Neurosci 1987; 7: 3371-3377.

[19] Perry VH. The ganglion cell layer of the retina of the rat: a Golgi study. Proc R Soc Lond Ser B 1979; 204: 363-375.

[20] Perry VH and Linden R. Evidence for dendritic competition in the developing retina. Nature 1982; 297: 683685.

[21] Perry VH and Maffei L. Dendritic competition: competition for what? Dev Brain Res 1988; 260: $195-208$.

[22] Rumoa AS, Campbell G and Shatz CJ. Transient morphological features of identified ganglion cells in living fetal: and neonatal retina. Science 1987; 237: 522-525.

[23] Reese BE and Cowey A. Large retinal ganglion cells in the rat: their distribution and laterality of projection. Exp Brain Res 1986: 61: 375-385.

[24] Wong-Riley MTT. Changes in the visual system of monocularly sutured or enuc]eated cats demonstrable with, cytochrome oxidase histochemistry. Brain Res 1979; 171: 11-28.

[25] Wong-Riley MTT. Cytochrome oxidase: an endogenous metabolic marker of neuronal activity. Trends in Neurosciences 1989; 12: 94-101.

[26] Wong-Riley MTT and Carroll EW. The effect of impulse blockage on cytochrome oxidase activity in the monkey visual system. Nature 1984; 307: 262-264.

Received 13-3-1990. Revised 15-5-1990. Accepted 28-5-1990. 
Jen LS and Chan RMW
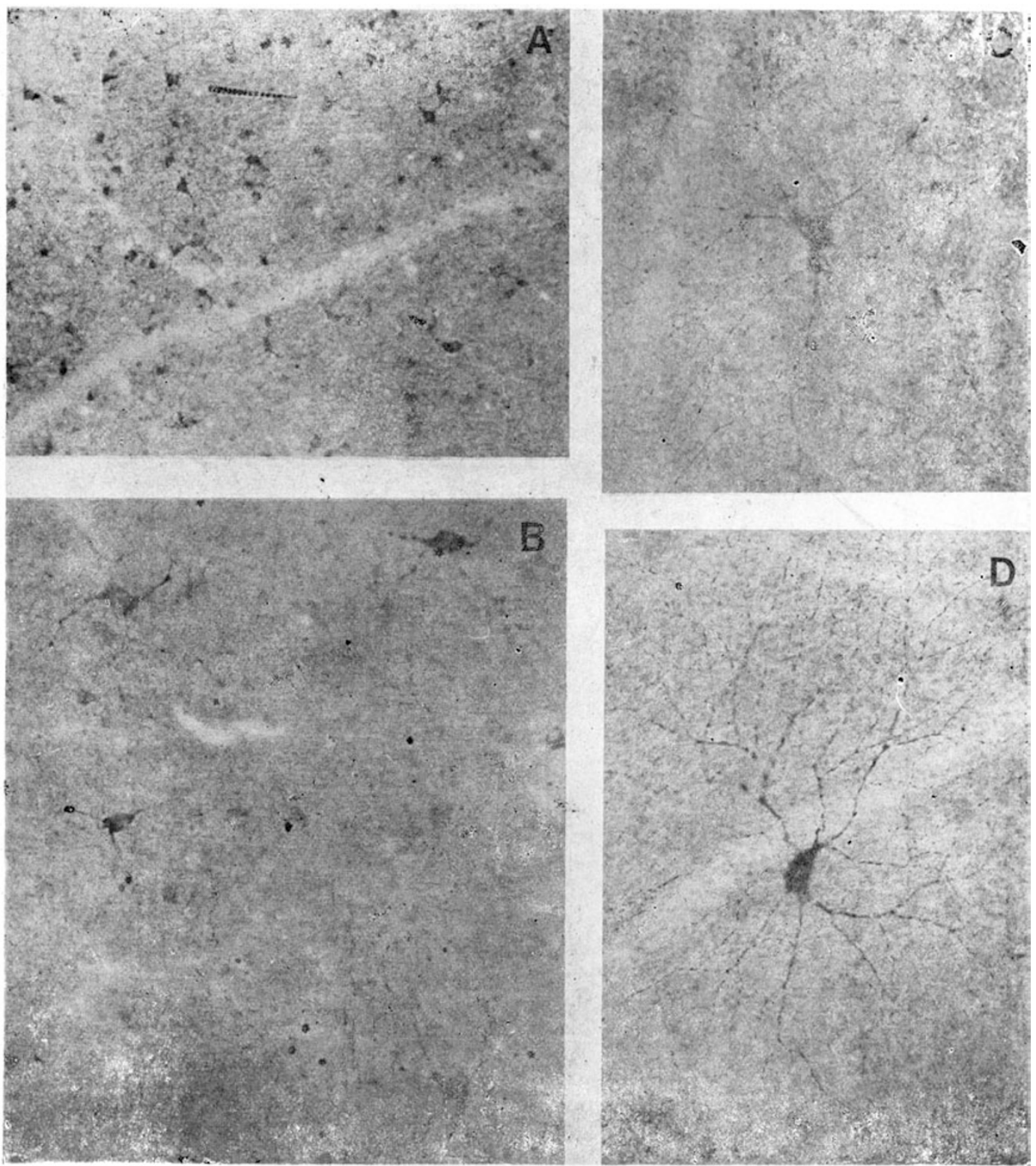

Fig. 3 Cytochrome oxidase rich ganglion cells in retinas of normal rats. (A) is a low power view of a portion of the peripheral nart of the temporal retina showing a fairly evenly distributed pattern of the cells across the retina. (B) shows several retinal ganglion cells which are moderately stained for cytochrome oxidase. (C) and (D) show two cytochrome oxidase reactive cells with slightly different dendritic morphology. Magnifications: A, $200 \times$; B, $600 \times ; \mathrm{C}$ and D, $700 \times$. 


\section{Cytochrome oxidase rich retinal ganglion cells}

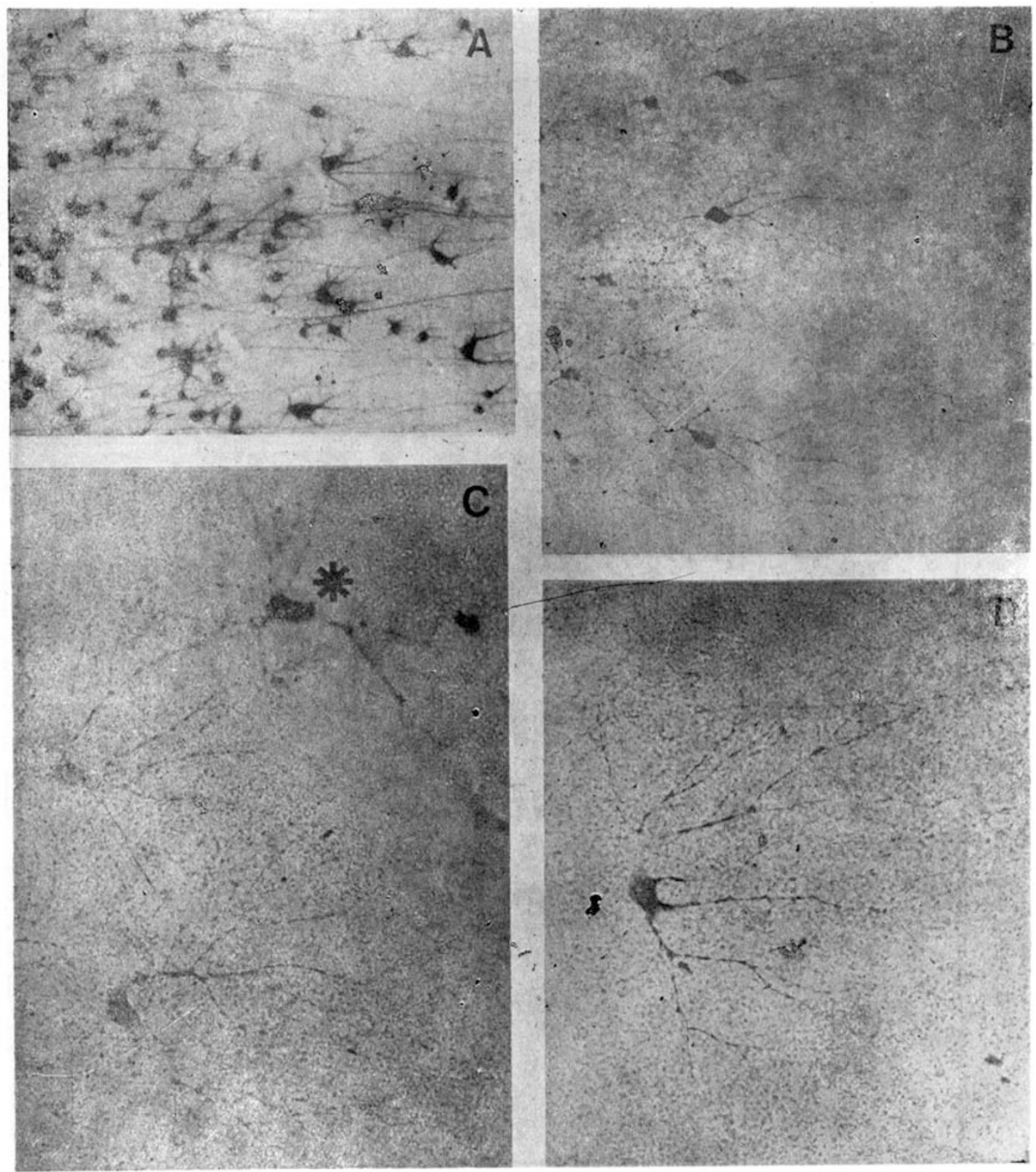

Fig. 4 Photomicrographs showing retinal ganglion cells labeled by WGA-HRP (A) or reactive for cytochrome oxidase (B-D) in rats with thalamic lesion made at birth. (A) shows a cluster of WGA-HRP labeled retinal ganglion cells located at the central border of the temporal crescent. These cells project to the ipsilateral side of the brain because the tracer was introduced to the right optic tract (see Fig. 1). (B-D) show retinal ganglion cells located in corresponding retinal regions but reacted for cytochrome oxidase histochemistry. Note the similar dendrtic orientation of the cells with strong bias towards to the nasal part of the retina to the left of the figures. The asterisk in (C) indicates a retinal ganglion cell with its dendrites ramifying in the deeper sublamina a in the inner plexiform layer and is therefore slightly out of focus. Magnifications: A, $250 \times ; \mathrm{B}, 250 \times$; C and D, $600 \times$. 